\title{
Ocean Acidification: Fish Physiology and Behavior ${ }^{1}$
}

\author{
Joshua Patterson, Lisa Krimsky, and Joseph Henry²
}

This document is one in a series on ocean acidification (OA). The series Introduction, Ocean Acidification: An Introduction, contains information on the causes and chemistry of OA. Because OA is very large-scale and complex, each document in the series addresses a specific aspect of this issue. Florida, with an extensive coastline and deep cultural and economic ties to marine resources, will be directly affected by changes in seawater chemistry. Thus, each topic in the series also highlights information of specific relevance for Florida.

\section{Introduction}

Increased atmospheric carbon dioxide $\left(\mathrm{CO}_{2}\right)$ has led to increased levels of dissolved $\mathrm{CO}_{2}$ in the Earth's oceans. This has generally decreased the $\mathrm{pH}$ of, or "acidified," ocean water. Decreased $\mathrm{pH}$, along with other chemical changes ultimately caused by an increase in dissolved $\mathrm{CO}_{2}$, could have direct effects on the physiology and behavior of fishes. ("Physiology" is the study of how an organism works; an organism's physiology refers to the biological systems that allow it to function and respond to its environment.) Scientists have dedicated a lot of time and effort to studying the potential effects of OA on fish physiology and behavior. This publication will summarize the current state of our understanding on the topic, with special emphasis on Florida fishes. It will also address current challenges in understanding the real-world effects of a complex global process using data largely collected on isolated fish in laboratory experiments.

\section{Ocean Acidification and Fish Physiology}

The most direct effects of $\mathrm{pH}$ on fish physiology occur in the respiratory and circulatory systems. Fish gills, similar to lungs in people, are respiratory organs designed to remove dissolved oxygen from the environment and transfer it into the blood. Blood is then circulated to the entire body to deliver these gases and other substances needed to sustain life. In people, most fishes, and indeed most vertebrates, blood $\mathrm{pH}$ is maintained within a relatively narrow range. This process is called acid-base regulation. Most fishes have several ways to regulate the $\mathrm{pH}$ of their blood, and studies have shown that they are able to do this when breathing water with much lower $\mathrm{pH}$ than that predicted for future seawater (Brauner and Baker 2009). While contradictory studies do exist, the consensus in scientific literature is that, in most fishes, basic indicators of physical fitness such as survival, aerobic capacity, and swimming speed are not affected by $\mathrm{pH}$ levels representing current or future OA conditions (Branch et al. 2013). This consensus is also supported by observations from aquaculture, where fish are often raised in $\mathrm{pH}$ drastically lower than predicted future values (Ellis et al. 2016). Having to perform more acid-base regulation should not threaten a fish's immediate survival, but as with any physiological response, acid-base regulation involves tradeoffs among body systems and comes at some biological cost to the animal (Heuer and Grosell 2014). For example, think of shivering when you are cold. While quite different from one another, both shivering and acid-base

1. This document is FA219, one of a series of the School of Forest Resources and Conservation, Program in Fisheries and Aquatic Sciences, UF/ IFAS Extension. Original publication date March 2020. Visit the EDIS website at https://edis.ifas.ufl.edu for the currently supported version of this publication.

2. Joshua Patterson, assistant professor, Program in Fisheries and Aquatic Sciences, School of Forest Resources and Conservation, UF/IFAS Extension and Florida Sea Grant, The Florida Aquarium's Center for Conservation; Lisa Krimsky, UF/IFAS Extension Florida Sea Grant Water Resources Regional Specialized Agent III, Southeast District; and Joseph Henry, graduate student, Program in Fisheries and Aquatic Sciences, School of Forest Resources and Conservation; UF/IFAS Extension, Gainesville, FL 32611.

The Institute of Food and Agricultural Sciences (IFAS) is an Equal Opportunity Institution authorized to provide research, educational information and other services

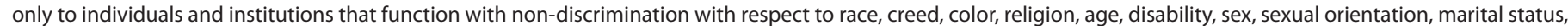

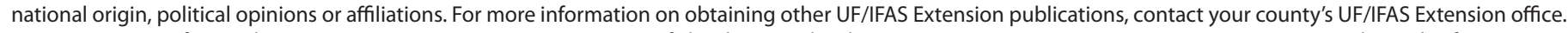
U.S. Department of Agriculture, UF/IFAS Extension Service, University of Florida, IFAS, Florida A \& M University Cooperative Extension Program, and Boards of County Commissioners Cooperating. Nick T. Place, dean for UF/IFAS Extension. 
regulation are physiological responses that require the use of energy and body systems that could be devoted to other ends, such as, for fish, spawning and reproduction.

Branch et al. (2013) reviewed several experiments testing for effects of OA on reproduction and early life stages of fish. While there is some variability among species, there have been generally no or limited effects on fish sperm motility or embryo development, even at oceanic levels of $\mathrm{pH} / \mathrm{CO}_{2}$ predicted for the year 2300. Hamilton et al. (2017) illustrated the importance of considering variability among species by simultaneously conducting identical experiments on two species of rockfish in the genus Sebastes. One species showed decreased swimming speed and aerobic capacity as $\mathrm{pH}$ decreased, while the other was not affected. These species-specific differences in sensitivity to OA make it important to consider the overall body of research on this topic and not give too much weight to any single result.

\section{Ocean Acidification and Fish Behavior}

While current consensus is that present day and future OA conditions have limited direct effects on basic physiological processes such as respiration and reproduction, an emerging body of literature suggests that more complex interactions of physiology and environment can be affected in potentially important ways. It is important to note that studying a complex trait such as behavior is much less straightforward than studying basic physiological processes such as respiration. When we refer to fish behavior, we mean the array of muscle and body movements fish make in response to sensory cues. Diverse sensory cues are interpreted in a fish's brain. The way the fish moves in response to its environment-how it behaves-is driven by its neural physiology, the systems in the fish's body that allow it to sense and react to its environment. Behavior involves interactions among the brain, sensory organs, and muscles, which are all connected by nerves. Decreased $\mathrm{pH}$ has been shown to affect senses in fish including sight (Ferrari et al. 2012) and hearing (Simpson et al. 2011), and especially the sense of smell, which is called olfaction. A review of published experiments determined that olfaction is the sense most affected by OA conditions (Cattano et al. 2018). Cattano et al. (2018) analyzed OA physiology experiments from 64 different studies covering 42 marine fish species from different areas of the world. Overall, OA affected fish behavior by decreasing direct response to sensory stimuli by $54 \%$ and increasing general activity levels by $108 \%$. In real-world terms, this resulted in things like decreased foraging for food and increased predation risk from higher activity and less propensity for hiding. Conversely, the size of overall effects on basic physiology ranged from a $7 \%$ increase in resting metabolic rate, which is the basic metabolism required to sustain the fish and does not include movements, to a $4 \%$ decrease in larval yolk reserves. Several basic physiological measurements including survival, metabolic scope, reproduction, and growth were unaffected by OA. Thus, Cattano et al. (2018) further support the conclusion that fishes are largely able to cope with OA at the most basic levels of physiology, but that senses and behaviors are affected. Interestingly, some research has suggested that the behavior of some fish living in areas that naturally experience low or fluctuating $\mathrm{pH}$, such as coastal upwelling zones, may be less affected by OA (Kwan et al. 2017). As noted in the previous section, species-specific differences are important to consider. Hamilton et al. (2017) studied a fish from the same area using a similar $\mathrm{pH}$ range and found that $\mathrm{OA}$ conditions disrupted behavior. Thus, while supported by some evidence, it should not be assumed that all fishes from naturally low or variable $\mathrm{pH}$ zones will be less affected by OA.

One interesting example of the effects of $\mathrm{OA}$ is on a behavior called lateralization. Individual fish are often either left or right "handed," which means that they have a pronounced tendency to turn one direction over the other. An early experiment on larval damselfish, which has been supported by others, showed that OA reduced lateralization, or decreased the "handedness," of these larvae (Domenici et al. 2012). This example demonstrates OA effects on a very basic brain function. Others better illustrate how behavioral changes might affect fish in real-world scenarios. Many coral reef fishes use the sense of smell to choose where to settle as larvae, avoid predators, or maintain a home range. Multiple studies have suggested that OA may impair these behaviors by affecting the sense of smell (Devine et al. 2012a; Devine et al. 2012b; Munday et al. 2009). OA has also been shown to decrease predator avoidance by affecting vision (Chung et al. 2014; Ferrari et al. 2012). Sensory effects that lead to behavior changes such as these have the potential to affect fish ecology by changing distributions and predator-prey interactions. Tresguerres and Hamilton (2017) provide a comprehensive review of the specific mechanisms thought to be responsible for OA effects on neural function in fishes. 


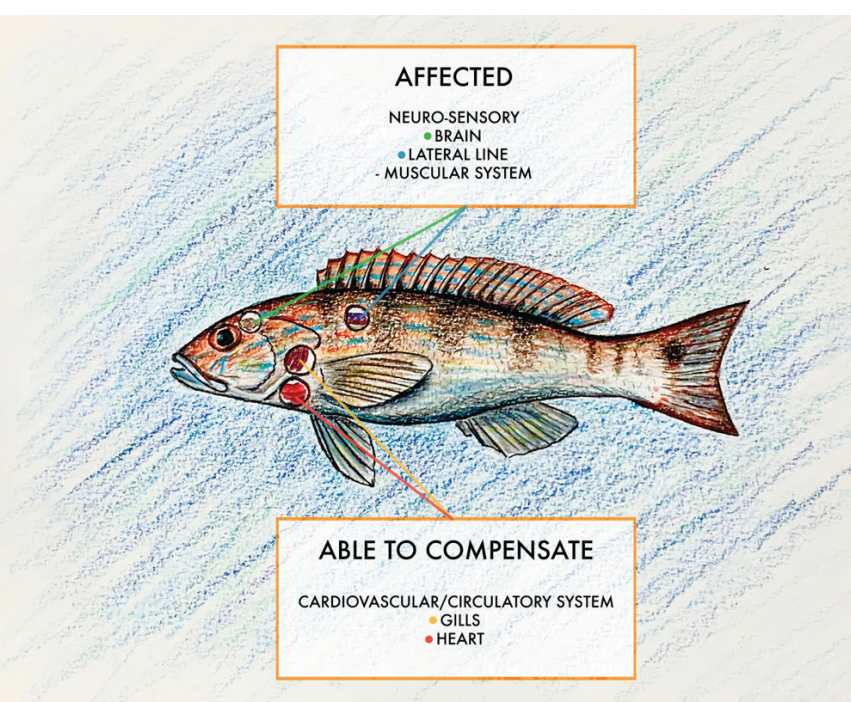

Figure 1. A graphical depiction generalizing what we understand about how OA affects different physiological systems in fish. Effects are species-specific, but studies are beginning to arrive at the consensus illustrated here.

\section{OA and Florida Fishes}

Florida is the only contiguous US state with coral reef ecosystems. Most of the sensory and behavioral studies to date have been on reef fishes and larvae. While these were primarily conducted on species from a different region of the globe-the Indo-Pacific - it is reasonable to expect that the negative impacts on neurological function observed in these studies would translate to coral reef fishes in Florida and the Caribbean.

The effects of OA on a few Florida native fishes have been studied directly. The inland silverside Menidia beryllina is a very common and widespread species that inhabits brackish water estuaries and freshwater habitats in Florida. A study by Baumann et al. (2012) found reduced growth (18\% decrease) and survival (78\% decrease) when inland silverside eggs and larvae were exposed to OA conditions through the first week after hatch. This result appears to contradict the previously stated consensus regarding growth and survival effects on marine fishes. Thus, this species, and newly hatched larvae generally, deserve further study. The Gulf toadfish Opsanus beta inhabits sand bottoms and seagrass meadows of shallow bays on Florida's Gulf Coast. A study of OA effects on acid-base regulation and respiratory physiology in this species was one of the first to support the general conclusions that neurosensory systems are compromised, and cardiovascular systems tend to compensate (Esbaugh et al. 2012). More recent work on red drum or redfish Sciaenops ocellatus, a very popular sportfish throughout coastal Florida, found that the species was able to compensate for OA conditions, but part of the compensation included physical changes in the gills (Esbaugh et al. 2016). Beyond these three studies, there is not a lot of readily available information on how $\mathrm{OA}$ affects Florida fishes. Given the species-specific nature of how OA affects fish and the relative scarcity of studies conducted on Florida natives, our understanding of how Florida's fisheries might be affected could be improved with additional study.

\section{Translating OA Effects on Fishes from Lab to Nature}

Most OA studies on fish physiology have been conducted in laboratories and were designed to exclude as many variables as possible and isolate the effects of OA on the fish. While this is necessary to understand how OA affects fish directly, it can make it difficult to translate results to the real world, which is full of variables and in constant flux. Recently, scientists have begun to study fishes at natural $\mathrm{CO}_{2}$ seeps, which may mimic future OA conditions, to see if behavioral changes noted in the lab translate to nature (Cattano et al. 2017; Milazzo et al. 2016; Munday et al. 2014). Multigenerational studies may also help to reveal what capacity fish have to adapt to OA across generations. Major questions that remain include (1) the ability of individual fish to acclimatize to lower $\mathrm{pH}$ over longer time periods or move to areas of higher $\mathrm{pH}$; (2) adaptive parental effects, or the possibility that parent fish exposed to OA produce offspring that are more resilient to this condition; and (3) the degree to which genetic variation and natural selection in fish will be affected by future OA conditions. Finally, a freely available paper (Browman 2016) introduces a set of articles that take a broader look at OA and how it might affect fishes and marine ecosystems generally. While we understand a great deal about how OA affects specific fish species, we are just beginning to scratch the surface of predicting what it might mean for future global fisheries.

\section{References}

Baumann, H., S. C. Talmage, and C. J. Gobler. 2012.

"Reduced Early Life Growth and Survival in a Fish in Direct Response to Increased Carbon Dioxide." Nature Climate Change 2(1): 38. doi:10.1038/nclimate1291

Branch, T. A., B. M. DeJoseph, L. J. Ray, and C. A. Wagner. 2013. "Impacts of Ocean Acidification on Marine Seafood." Trends in Ecology \& Evolution 28(3): 178-186. doi:10.1016/j.tree.2012.10.001 
Brauner, C. J., and D. W. Baker. 2009. "Patterns of Acid-Base Regulation during Exposure to Hypercarbia in Fishes." In Cardio-Respiratory Control in Vertebrates. Glass, M. and Wood, S., eds., 43-63. Springer, Berlin, Heidelberg. doi:10.1007/978-3-540-93985-6_3

Browman, H. I. 2016. "Applying Organized Scepticism to Ocean Acidification Research." 73(3): 529-536. doi:10.1093/ icesjms/fsw010

Cattano, C., A. Calò, A. Di Franco, R. Firmamento, F. Quattrocchi, K. Sdiri, P. Guidetti, and M. Milazzo. 2017. "Ocean Acidification Does not Impair Predator Recognition but Increases Juvenile Growth in a Temperate Wrasse Off $\mathrm{CO}_{2}$ Seeps." Marine Environmental Research 132: 33-40. doi: 10.1016/j.marenvres.2017.10.013

Cattano, C., J. Claudet, P. Domenici, and M. Milazzo. 2018. "Living in a High $\mathrm{CO}_{2}$ World: A Global Meta-Analysis Shows Multiple Trait-Mediated Fish Responses to Ocean Acidification." Ecological Monographs 88(3): 320-335. doi:10.1002/ecm.1297

Chung, W. S., N. J. Marshall, S. A. Watson, P. L. Munday, and G. E. Nilsson. 2014. "Ocean Acidification Slows Retinal Function in a Damselfish through Interference with GABAA Receptors." Journal of Experimental Biology 217(3): 323-326. doi:10.1242/jeb.092478

Devine, B. M., P. L. Munday, and G. P. Jones. 2012a. "Homing Ability of Adult Cardinalfish Is Affected by Elevated Carbon Dioxide." Oecologia 168(1): 269-276. doi:10.1007/ s00442-011-2081-2

Devine, B. M., P. L. Munday, and G. P. Jones. 2012b. "Rising $\mathrm{CO}_{2}$ Concentrations Affect Settlement Behaviour of Larval Damselfishes." Coral Reefs 31(1): 229-238. doi:10.1007/ s00338-011-0837-0

Domenici, P., B. Allan, M. I. McCormick, and P. L. Munday. 2012. "Elevated Carbon Dioxide Affects Behavioural Lateralization in a Coral Reef Fish.” Biology Letters 8(1): 78-81. doi:10.1098/rsbl.2011.0591

Ellis, R. P., M. A. Urbina, and R. W. Wilson. 2017. "Lessons from Two High $\mathrm{CO}_{2}$ Worlds-Future Oceans and Intensive Aquaculture." Global Change Biology 23(6): 2141-2148. doi:10.1111/gcb.13515

Esbaugh, A. J., R. Ern, W. M. Nordi, and A. S. Johnson. 2016. "Respiratory Plasticity Is Insufficient to Alleviate Blood Acid-Base Disturbances after Acclimation to Ocean
Acidification in the Estuarine Red Drum, Sciaenops ocellatus." Journal of Comparative Physiology B 186(1): 97-109. doi:10.1007/s00360-015-0940-6

Esbaugh, A. J., R. Heuer, and M. Grosell. 2012. "Impacts of Ocean Acidification on Respiratory Gas Exchange and Acid-Base Balance in a Marine Teleost, Opsanus beta.' Journal of Comparative Physiology B 182(7): 921-934. doi:10.1007/s00360-012-0668-5

Ferrari, M. C., M. I. McCormick, P. L. Munday, M. G. Meekan, D. L. Dixson, O. Lönnstedt, and D. P. Chivers. 2012. "Effects of Ocean Acidification on Visual Risk Assessment in Coral Reef Fishes." Functional Ecology 26(3): pp.553-558. doi:10.1111/j.1365-2435.2011.01951.x

Hamilton, S. L., C. A. Logan, H. W. Fennie, S. M. Sogard, J. P. Barry, A. D. Makukhov, L. R. Tobosa, K. Boyer, C. F. Lovera, and G. Bernardi. 2017. "Species-Specific Responses of Juvenile Rockfish to Elevated $\mathrm{pCO}_{2}$ : From Behavior to Genomics." PloS One 12(1): e0169670. doi:10.1371/journal. pone. 0169670

Heuer, R. M., and M. Grosell. 2014. "Physiological Impacts of Elevated Carbon Dioxide and Ocean Acidification on Fish." American Journal of Physiology-Regulatory, Integrative and Comparative Physiology 307: 1061-1084. doi:10.1152/ ajpregu.00064.2014

Kwan, G. T., T. J. Hamilton, and M. Tresguerres. 2017. $\mathrm{CO}_{2}^{-}$ Induced Ocean Acidification Does not Affect Individual or Group Behaviour in a Temperate Damselfish. Royal Society Open Science 4:170283. doi: 10.1098/rsos.170283

Milazzo, M., C. Cattano, S. H. Alonzo, A. Foggo, M. Gristina, R. Rodolfo-Metalpa, M. Sinopoli, D. Spatafora, K. A. Stiver, and J. M. Hall-Spencer. 2016. "Ocean Acidification Affects Fish Spawning but not Paternity at $\mathrm{CO}_{2}$ Seeps." Proceeding of the Royal Society B. 283(1835): 20161021. doi:10.1098/rspb.2016.1021

Munday, P. L., A. J. Cheal, D. L. Dixson, J. L. Rummer, and K. E. Fabricius. 2014. "Behavioural Impairment in Reef Fishes Caused by Ocean Acidification at $\mathrm{CO}_{2}$ Seeps." Nature Climate Change 4(6): 487. doi: 10.1038/nclimate2195

Munday, P. L., D. L. Dixson, J. M. Donelson, G. P. Jones, M. S. Pratchett, G. V. Devitsina, and K. B. Døving. 2009. "Ocean Acidification Impairs Olfactory Discrimination and Homing Ability of a Marine Fish." Proceedings of the National Academy of Sciences 106(6): 1848-1852. doi:10.1073/pnas.0809996106 
Simpson, S. D., P. L. Munday, M. L. Wittenrich, R. Manassa, D. L. Dixson, M. Gagliano, and H. Y. Yan. 2011. "Ocean Acidification Erodes Crucial Auditory Behaviour in a Marine Fish.” Biology Letters 7(6): p.rsbl20110293. doi:10.1098/ rsbl.2011.0293

Tresguerres, M., and T. J. Hamilton. 2017. "Acid-base Physiology, Neurobiology and Behaviour in Relation to $\mathrm{CO}_{2}$-Induced Ocean Acidification." Journal of Experimental Biology 220(12): 2136-2148. doi: 10.1242/jeb.144113 